\title{
Contraction of intestinal effector T cells by retinoic acid-induced purinergic receptor P2X7
}

\author{
S Hashimoto-Hill ${ }^{1}$, L Friesen ${ }^{1,2}, \mathrm{M} \mathrm{Kim}^{1}$ and $\mathrm{CH} \mathrm{Kim}^{1,2,3,4,5}$
}

The intestinal environment harbors a large number of activated T cells, which are potentially inflammatory. To prevent inflammatory responses, intestinal Tcells are controlled by various tolerogenic mechanisms, including T-cell apoptosis. We investigated the expression mechanism and function of the purinergic receptor P2X7 in contraction of intestinal $\mathrm{CD}^{+}$effector T cells. We found that P2X7 upregulation on $\mathrm{CD} 4^{+}$effector $\mathrm{T}$ cells is induced by retinoic acid through retinoic acid receptor $\alpha$ binding to an intragenic enhancer region of the $P 2 r x 7$ gene. $\mathrm{P} 2 \mathrm{X} 7$ is highly expressed by most intestinal $\alpha \beta$ and $\gamma \delta$ T cells, including T-helper type 1 (Th1) and Th17 cells. The intestinal effector T cells are effectively deleted by P2X7 activation-dependent apoptosis. Moreover, P2X7 activation suppressed T-cell-induced colitis in Rag $^{-1-}$ mice. The data from vitamin A-deficient and $P 2 r x 7^{-1-}$ mice indicate that the retinoic acid-P2X7 pathway is important in preventing aberrant buildup of activated T cells. We conclude that retinoic acid controls intestinal effector T-cell populations by inducing P2X7 expression. These findings have important ramifications in preventing inflammatory diseases in the intestine.

\section{INTRODUCTION}

The intestinal immune system is in a state of constant activation because of the ample presence of foreign antigens and microbial products in the gut lumen. The majority of intestinal CD4 ${ }^{+} \mathrm{T}$ cells are activated cells, and many of these $\mathrm{T}$ cells recognize antigens generated by commensal bacteria. ${ }^{1}$ Although intestinal effector $\mathrm{T}$ cells have important roles in regulating the gut microbiota and mounting immune responses to pathogens, activated $\mathrm{T}$ cells can mediate adverse inflammatory responses, leading to colitis, allergic responses, or other chronic inflammatory diseases. To prevent inflammatory responses, the intestinal immune system must have effective tolerance mechanisms. Major mechanisms of immune tolerance in the intestine include generation and maintenance of FoxP3 ${ }^{+}$and/or IL-10 ${ }^{+}$(interleukin-10-positive) regulatory $\mathrm{T}$ cells (Tregs), induction of anergic lymphocytes, and disposal of excessive effector cells, the latter of which is called effector cell contraction. ${ }^{2,3}$ T-cell contraction is mediated by apoptotic signaling induced by activation-induced cell death pathways mediated by FAS/FAS ligand, perforin, T-cell receptor proximal kinases, reactive oxygen species, and P2X7 signaling. ${ }^{4-10}$
$\mathrm{P} 2 \mathrm{X} 7$ is a purinergic receptor and adenosine triphosphate (ATP)-gated cation channel. ${ }^{11}$ P2X7 is activated by nicotinamide adenine dinucleotide (NAD)-induced adenosine diphosphate (ADP) ribosylation, which is catalyzed by the enzyme ADP-ribosyltransferase 2 (ART2) in rodents. ${ }^{12}$ P2X7 is also activated by high levels of extracellular ATP. ${ }^{13}$ Activation of P2X7 induces rapid influx of cations, intracellular signaling, and pore formation on the cell membrane for apoptosis. ${ }^{14} \mathrm{P} 2 \mathrm{X} 7$ is expressed by T cells, macrophages, mast cells, epithelial cells, and neuronal cells. ${ }^{15-17}$ P2X7 activation can lead to inflammasome activation and cytokine expression in monocytic lineage cells. ${ }^{18-20}$ T-cell subsets such as FoxP3 ${ }^{+} \mathrm{T}$ cells, cytotoxic T cells, and follicular helper T cells express P2X7 and are sensitive to P2X7-mediated cell death, ${ }^{4,5,21,22}$ which can either suppress or enhance immunity depending on the function of each cell type. In humans, loss-of-function polymorphisms in the $P 2 R X 7$ gene are linked to chronic lymphocytic leukemia and increased susceptibility to pathogens such as Mycobacterium tuberculosis. ${ }^{23,24}$ It has been reported that naïve/resting $\mathrm{CD}^{+}{ }^{+} \mathrm{T}$ cells and retinoic acid (RA)-treated $\mathrm{CD} 8{ }^{+} \mathrm{T}$ cells express $\mathrm{P} 2 \mathrm{X} 7,,^{4,25}$ but the expression

${ }^{1}$ Laboratory of Immunology and Hematopoiesis, Department of Comparative Pathobiology, West Lafayette, Indiana, USA. ${ }^{2}$ Weldon School of Biomedical Engineering, West Lafayette, Indiana, USA. ${ }^{3}$ Department of Biological Sciences, West Lafayette, Indiana, USA. ${ }^{4}$ Purdue Institute of Inflammation, Immunology and Infectious Diseases, West Lafayette, Indiana, USA and ${ }^{5}$ Purdue Center for Cancer Research, Purdue University, West Lafayette, Indiana, USA. Correspondence: C Kim (chkim@purdue.edu) 
mechanism and the function of P2X7 in intestinal T-cell homeostasis remain poorly elucidated.

We studied the regulation mechanism of $P 2 r x 7$ expression and the function of $\mathrm{P} 2 \mathrm{X} 7$ in regulating effector $\mathrm{T}$ cells, particularly T-helper type 1 (Th1) and Th17 cells, in the intestine. Here, we report that RA induces P2X7 expression in Th1 and Th17 cells in the intestine by activating an RAresponsive enhancer region in the mouse $P 2 r x 7$ gene. P2X7 deficiency leads to aberrant expansion of Th1 and Th17 cells in the small intestine (SI). NAD-dependent ADP ribosylation of P2X7 induces the contraction of intestinal Th1 and Th17 cell populations in the steady state and during active immune responses to bacterial pathogens. NAD treatment also depleted inflammatory effector $\mathrm{T}$ cells and suppressed tissue inflammation in the intestine. Our results provide a regulatory mechanism for P2X7 expression in effector T cells and identify a role for the RA-induced $\mathrm{P} 2 \mathrm{X} 7$ in the control of inflammatory $\mathrm{T}$ cells in the intestine.

\section{RESULTS}

\section{RA induces the expression of $P 2 r x 7$ and $A r t 2 b$ in intestinal $\mathrm{CD}^{+}{ }^{+} \mathrm{T}$ cells}

Transcriptome analysis of cultured mouse $\mathrm{CD}^{+}{ }^{+} \mathrm{T}$ cells revealed that $P 2 r \times 7$ expression is induced by RA but suppressed by an RA receptor $\alpha(\mathrm{RAR} \alpha)$ antagonist, Ro41-5253 (Figure 1a). A follow-up real-time reverse transcriptionPCR examination confirmed that RA greatly induced P2rx7 expression, whereas the RAR $\alpha$ antagonist Ro41-5253 suppressed its expression in cultured $\mathrm{CD}^{+} \mathrm{T}$ cells (Figure 1b). Along with P2rx7, the expression of the gene for the ADP-ribosyltransferase (ART2.2), Art2b, was also induced by RA (Figure 1b). Using a highly sensitive three-step antibody staining method, we also found that RA induces P2X7 protein expression on the surface of activated $\mathrm{CD} 4{ }^{+} \mathrm{T}$ cells (Figure 1c). To further study the impact of RA on P2X7 expression in vivo, we used vitamin A-deficient (VAD) mice and examined $\mathrm{P} 2 \mathrm{X} 7$ expression by $\mathrm{CD} 4{ }^{+} \mathrm{T}$ cells in the SI, colon, mesenteric lymph node (MLN), and spleen in vivo. We found that SI and large intestinal (LI) $\mathrm{CD} 4^{+} \mathrm{T}$ cells highly expressed P2X7, whereas those in lymphoid tissues expressed P2X7 only at basal levels (Figure 1d). Importantly, the P2X7 expression on intestinal $\mathrm{CD} 4^{+} \mathrm{T}$ cells was greatly decreased in VAD mice (Figure 1d), indicating a positive role of vitamin A in $\mathrm{P} 2 \mathrm{X} 7$ expression by $\mathrm{CD}^{+} \mathrm{T}$ cells. Immunofluorescence staining revealed that most $\mathrm{CD} 4^{+} \mathrm{T}$ cells in the lamina propria (LP), along with intraepithelial $\mathrm{T}$ cells, expressed P2X7 in intestinal villi (Figure 1e).

\section{The sensitivity of the $P 2 r \times 7$ gene to RA is regulated by an intragenic enhancer region}

RA induces gene expression by activating RAR-RXR receptors that bind RA-responsive elements on many genes. Analysis of published chromatin immunoprecipitation (ChIP)-sequencing data $^{26}$ indicates the presence of two major intragenic RAR $\alpha$ binding regions (I and II) in the mouse P2rx7 gene (Figure 2a). However, the putative $P 2 r x 7$ promoter region did not have any significant RAR $\alpha$-binding activity. The RAR $\alpha$-binding regions had epigenetic modifications such as H3K4me and H3K27Ac, which are consistent with high transcriptional activity. ${ }^{27} \mathrm{~T}$-cell activation in the presence of RA-induced RAR $\alpha$ binding and histone $3(\mathrm{H} 3)$ acetylation on region II (Figure 2b). The enhancer activity of region II, which is located between exons 2 and 3 , was tested in primary $\mathrm{CD} 4^{+} \mathrm{T}$ cells by a luciferase reporter assay. RA-dependent transcriptional reporter activity was detected when region II was ligated downstream of the P2rx7 promoter in the luciferase reporter plasmid (Figure 2c). Therefore, this region has an RA-dependent enhancer activity and is referred to as "the RA-responsive P2rx7 enhancer."

\section{RA makes $\mathrm{CD}^{+}{ }^{+} \mathrm{T}$ cells susceptible to NAD-induced apoptosis in a P2X7-dependent manner}

$\mathrm{P} 2 \mathrm{X} 7$ activation on $\mathrm{T}$ cells induces phosphatidylserine exposure and apoptosis. ${ }^{14}$ Because of the differential expression of P2X7 by RA- and Ro41-5253-treated T cells, we compared their sensitivity with NAD-induced apoptosis. RA-treated $\mathrm{CD} 4{ }^{+} \mathrm{T}$ cells were highly sensitive to NAD-induced apoptosis, whereas Ro41-5253-treated T cells were insensitive to NAD (Figure 3a). This dependence on RA was observed on $\mathrm{CD} 4{ }^{+} \mathrm{T}$ cells, activated with different $\mathrm{T}$-cell activators such as concannavalin A (Figure 3a) and $\mathrm{OVA}_{323-339}$ (not shown). oATP (oxidized ATP; an irreversible antagonist for P2X7) effectively blocked the NAD-induced apoptosis. Moreover, the $\mathrm{CD} 4^{+} \mathrm{T}$ cells, isolated from the MLN of vitamin A-normal (VAN) mice, were significantly more susceptible to NAD-induced apoptosis than their counterparts from VAD mice (Figure $3 \mathbf{b}$ ). Next, we examined the sensitivity of intestinal T cells to NAD-induced apoptosis in vivo following intravenous injection of NAD into mice. The $\mathrm{CD} 4^{+} \mathrm{T}$ cells of the SI of VAN mice were effectively depleted following NAD injection, whereas those in VAD mice were resistant to NAD-induced cell death (Figure 3c). While wild-type (WT) T cells, induced for P2X7 expression with RA in vitro, were sensitive to NAD-induced apoptosis, $P 2 r x 7^{-1-}$ $\mathrm{CD} 4{ }^{+} \mathrm{T}$ cells were resistant (Figure 3d). These results indicate that RA induces the expression of functional P2X7 on intestinal $\mathrm{CD} 4{ }^{+} \mathrm{T}$ cells and $\mathrm{P} 2 \mathrm{X} 7$ activation depletes intestinal $\mathrm{CD} 4{ }^{+} \mathrm{T}$ cells.

Polymorphisms in the P2rx7 gene in C57BL/6 and BALB/c mice have been reported, leading to functional differences in P2X7 activity. ${ }^{28}$ Because of this polymorphism, we also examined P2X7 expression and function in regulating $\mathrm{T}$ cells in $B A L B / c$ mice. We found that the $T$ cells from $B A L B / c$ mice expressed $\mathrm{P} 2 \mathrm{X} 7$ in response to RA and were equally sensitive to NAD-induced apoptosis (Supplementary Figure 1a-d online).

There are many $\alpha \beta$ and $\gamma \delta$ T-cell subsets in the LP and intraepithelial compartments. We studied P2X7 expression by CD4- and/or CD8-expressing $\alpha \beta$ and $\gamma \delta$ T-cell subsets in the SI LP and intraepithelial compartments. We found that all of the $\alpha \beta\left(\mathrm{CD} 4^{+} \mathrm{CD} 8 \alpha^{+}, \mathrm{CD} 4^{+} \mathrm{CD} 8 \alpha^{-}, \mathrm{CD} 8 \alpha^{+} \mathrm{CD} 8 \beta^{+}\right.$, and $\left.\mathrm{CD} 8 \alpha^{++}\right)$and $\gamma \delta\left(\mathrm{CD} 8 \alpha^{++}\right.$and $\left.\mathrm{CD} 8^{-} \mathrm{CD} 4^{-}\right)$T-cell subsets highly expressed $\mathrm{P} 2 \mathrm{X} 7$ and were susceptible to NADinduced cell death (Figure 4a,b). 


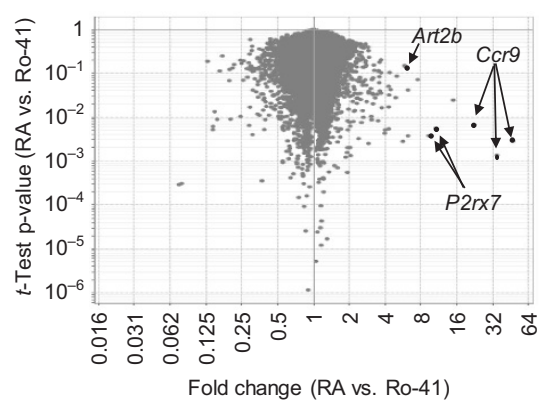

C

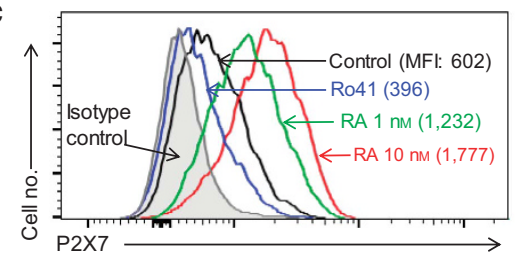

b
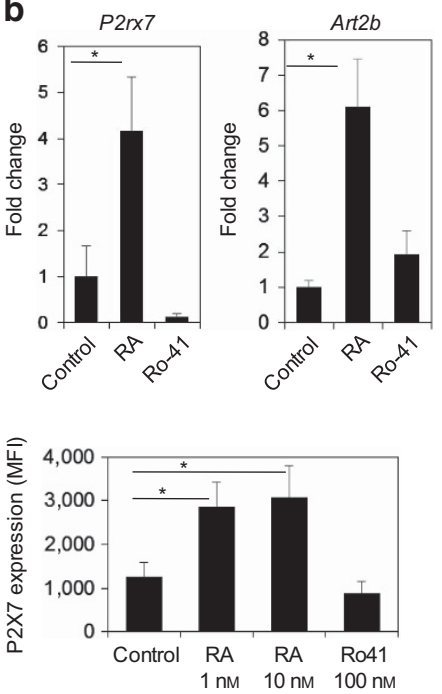

d
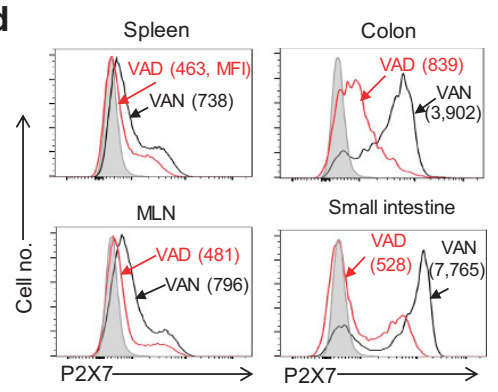

Small intestine
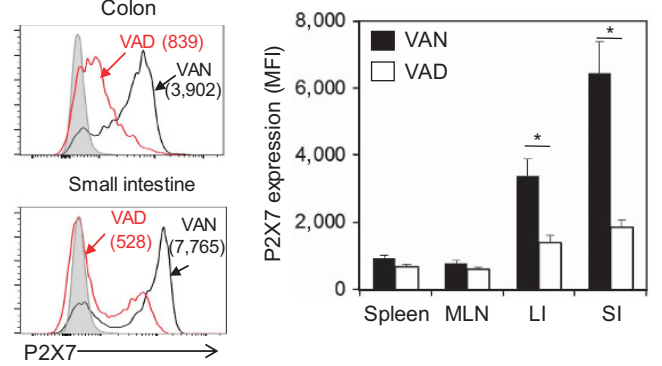

e
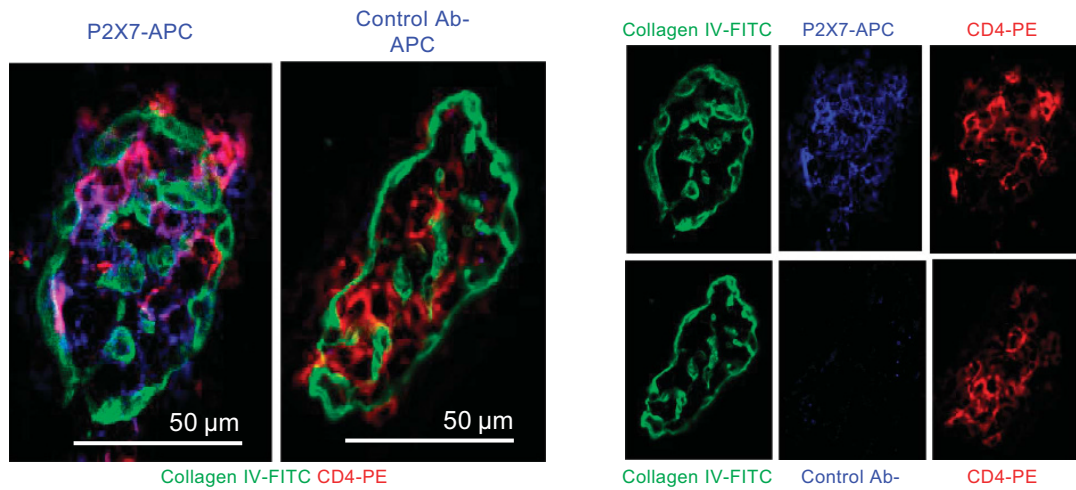

APC

Figure 1 Retinoic acid (RA) induces P2X7 expression in CD4 ${ }^{+}$T cells in vitroand in vivo. (a) A volcano plot for genes up- or downregulated by RA

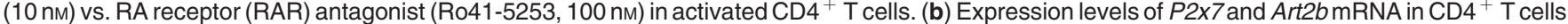
activated in the presence of RA or Ro41-5253. Relative expression levels of $P 2 r x 7$ and Art2b mRNA are shown. (c) Expression of surface P2X7 protein on $\mathrm{CD} 4{ }^{+} \mathrm{T}$ cells activated in the presence of RA or Ro41-5253. Mean fluorescence intensity (MFI) of P2X7 staining determined by flow cytometry is shown Naïve CD4 ${ }^{+}$T cells were cultured with concanavalin A (a and c) or anti-CD3/CD28 (b) in the presence of interleukin-2 (IL-2) and RA (or Ro41-5253) for 3 (a and b) or 5 (c) days. (d) CD4 ${ }^{+} \mathrm{T}$ cells from the spleen, mesenteric lymph node (MLN), the lamina propria (LP) of the small intestine (SI), and the LP of the large intestine (LI) of vitamin A-normal (VAN) and vitamin A-deficient (VAD) mice were examined for P2X7 expression by flow cytometry. (e) Expression of P2X7 by T cells in intestinal villi. Confocal microscopy was performed on fluorescent antibody-stained frozen sections of SI tissues (original magnification $\times 250)$. Representative and combined data $(n=3$ for $\mathbf{b}$, $\mathbf{c}$, and $\mathbf{d} ; n=5$ for $\mathbf{e})$ are shown. All error bars indicate s.e.m. ${ }^{*}$ Significant differences from control or between two groups. FITC, fluoroscein isothiocyanate; PE, phycoerythrin.

Antigenically stimulated memory/effector, but not naïve, $\mathrm{CD}^{+} \mathrm{T}$ cells preferentially express P2X7

It has been proposed that naïve or resting $\mathrm{CD} 4{ }^{+} \mathrm{T}$ cells preferentially express $\mathrm{P} 2 \mathrm{X} 7$ and are the main target of NAD-induced cell death. ${ }^{25}$ However, our data indicate that $\mathrm{P} 2 \mathrm{X} 7$ expression is induced by RA on intestinal $\mathrm{T}$ cells, the majority of which are memory or effector $\mathrm{T}$ cells. Therefore, we closely examined the P2X7 expression by resting vs. activated cells based on CD69 expression and naive vs. memory/effector-like $\mathrm{T}$ cells based on CD62L/CD44 expression. P2X7 expression on SI $\mathrm{CD}^{+} \mathrm{T}$ cells was concentrated on $\mathrm{CD} 9^{+}$activated $\mathrm{T}$ cells compared with $\mathrm{CD}^{-} 9^{-} \mathrm{CD}^{+}$cells (Figure 5a). Similarly, CD69 ${ }^{+} \mathrm{CD} 4^{+}$ cells, generated in culture in the presence of RA, 
a

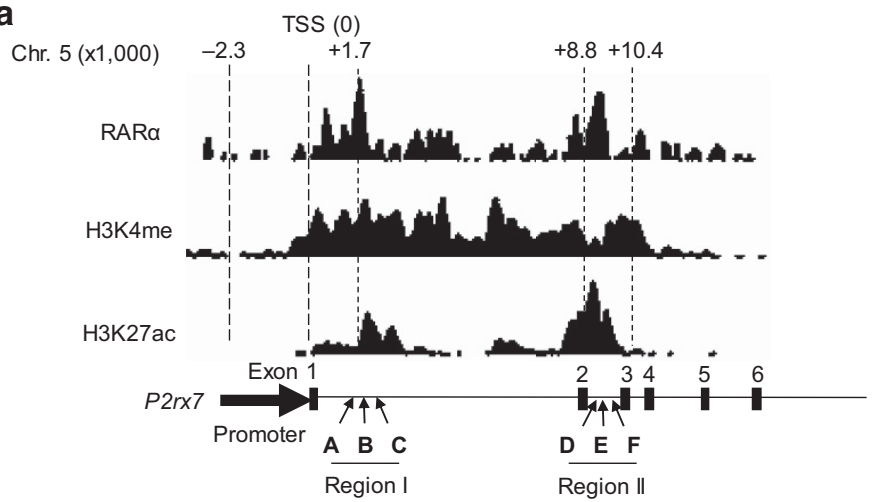

b
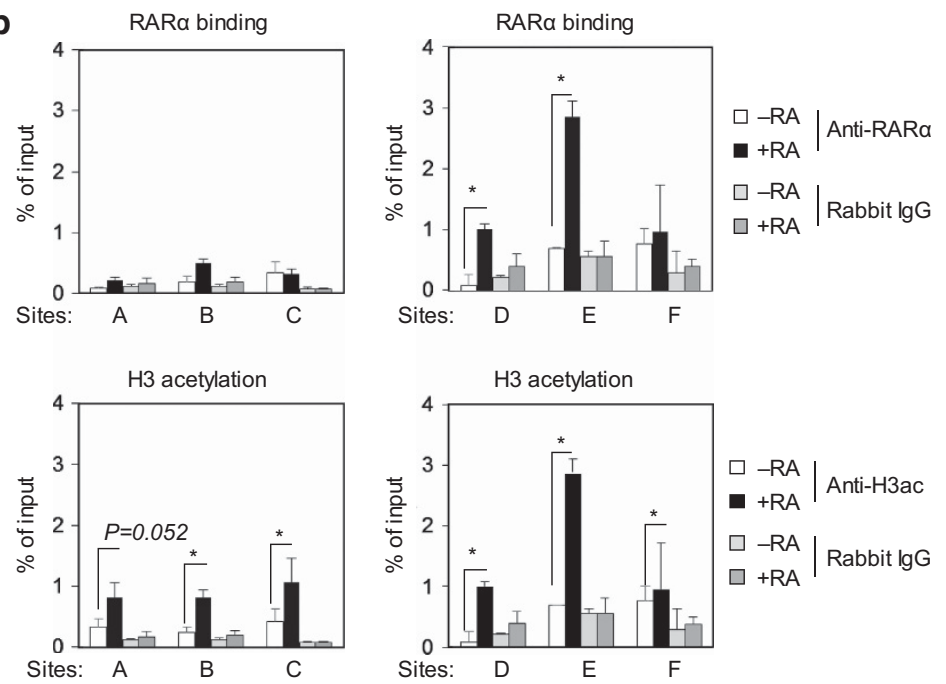

C

pGL4.10-pP2rx7-luc:

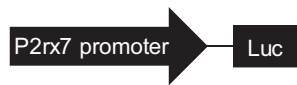

pGL4.10-pP2rx7-Enhancer-Luc:

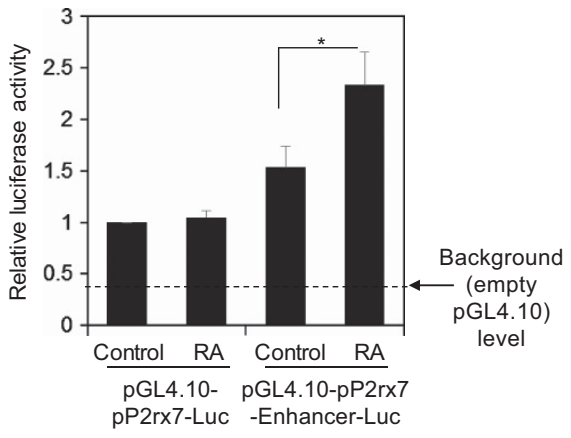

Figure 2 An enhancer region in the P2X7gene has binding sites for retinoic acid (RAR $\alpha$ ) and makes the $P 2 X 7$ gene responsible to RA. (a) The structure of $P 2 r x 7$ promoter and enhancer regions along with RAR $\alpha$ binding, H3K4 methylation, and H3K27 acetylation. (b) RAR $\alpha$ binding and histone 3 (H3) acetylation at putative P2rx7 enhancer regions. A chromatin immunoprecipitation (ChIP) assay was performed using anti-RAR $\alpha$ and anti-acetylated $\mathrm{H} 3$ on $\mathrm{CD}^{+}{ }^{+}$naïve T cells activated with anti-CD3/CD28 for 3 days in the presence of RA or Ro41-5253. (c) The transcriptional activity of the P2rx7 enhancer region was determined with a luciferase reporter assay. Reporter plasmids were transfected into activated CD4 ${ }^{+} \mathrm{T}$ cells, cultured for $6 \mathrm{~h}$ in the presence or absence of RA, and assayed for luciferase activity. Relative luciferase units (RLUs) normalized by PGL4-P2rx7 control levels are shown. Combined data from three to six independent experiments are shown. *Significant differences between indicated groups. IgG, control immunoglobulin G.

expressed higher levels of $\mathrm{P} 2 \mathrm{X} 7$ than did $\mathrm{CD} 69^{-} \mathrm{CD} 4^{+}$cells (Figure 5b). Moreover, P2X7 expression highly correlated with the expression of the memory/effector $\mathrm{T}$ cell marker CD44 and was negligible on $\mathrm{CD} 62 \mathrm{~L}^{+} \mathrm{CD} 44^{-}$ naïve-like $\mathrm{CD}^{+} \mathrm{T}$ cells (Figure $5 \mathbf{c}$ ). In line with the pattern of $\mathrm{P} 2 \mathrm{X} 7$ expression, NAD injection effectively depleted memory/effector CD62 $\mathrm{L}^{-} \mathrm{CD} 44^{+} \mathrm{CD}^{+} \mathrm{T}$ cells but not naïve-type $\mathrm{CD}_{2} \mathrm{~L}^{+} \mathrm{CD}_{4} 4^{-} \mathrm{CD}^{+} \quad \mathrm{T}$ cells
(Figure 5d). Because it was previously reported that FoxP3 $^{+} \mathrm{T}$ cells highly express $\mathrm{P} 2 \mathrm{X} 7,{ }^{22}$ we also examined $\mathrm{P} 2 \mathrm{X} 7$ expression by FoxP3 ${ }^{+} \mathrm{T}$ cells. For CD62 $\mathrm{L}^{+} \mathrm{CD} 44^{-}$ naïve types, $\mathrm{P} 2 \mathrm{X} 7$ expression was higher on $\mathrm{FoxP}^{+}{ }^{+} \mathrm{T}$ cells, whereas it was higher on $\mathrm{CD} 44^{+} \mathrm{FoxP}^{-}$memory $\mathrm{T}$ cells compared with $\mathrm{CD}_{4} 4^{+} \mathrm{FoxP}^{+}$memory $\mathrm{T}$ cells (Supplementary Figure 2a online). In culture, RA induced P2X7 expression both in FoxP3 ${ }^{-}$and FoxP3 ${ }^{+} \mathrm{CD}^{+}{ }^{+} \mathrm{T}$ cells 

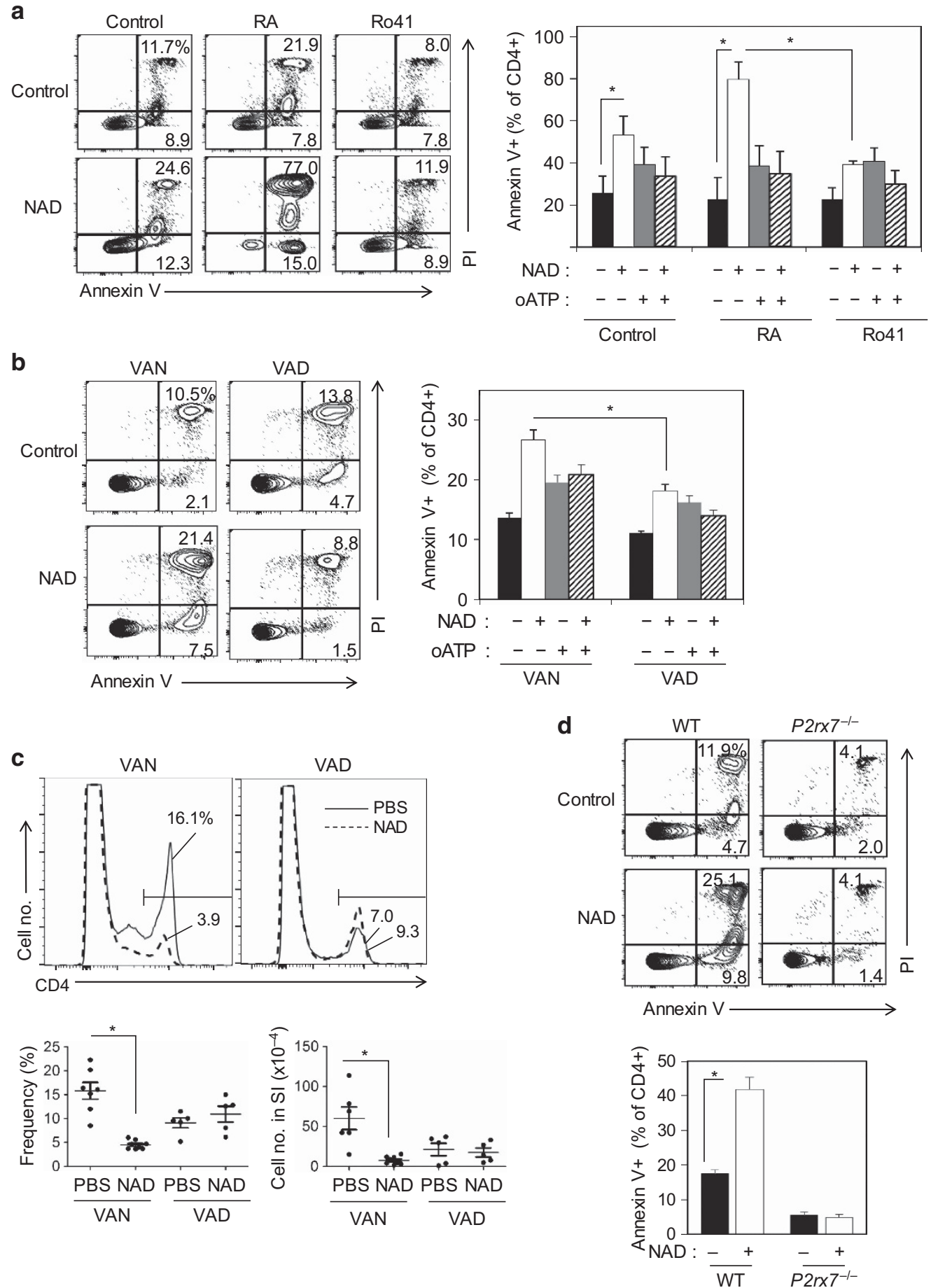

Figure 3 Retinoic acid (RA) increases CD4 ${ }^{+}$T-cell sensitivity to nicotinamide adenine dinucleotide (NAD)-induced cell death in vitro and in vivo. (a) RA-treated CD4 ${ }^{+}$T cells are more susceptible than Ro41-treated CD4 ${ }^{+}$T cells to NAD-induced cell death. Naïve CD4 ${ }^{+} \mathrm{T}_{\text {cells were cultured }}$ with concanavalin A in the presence of interleukin-2 (IL-2) and RA (or Ro41-5253) for 4-5 days. The cells were treated with NAD (100 $\mu \mathrm{M}$ ) or control media for $2 \mathrm{~h}$, and the frequency of apoptotic $\mathrm{CD} 4^{+}$cells was determined by annexin $\mathrm{V}$ and propidium iodide (PI) staining. (b) Mesenteric lymph node (MLN) $\mathrm{CD} 44^{+}$ T cells isolated from vitamin A-deficient (VAD) mice were relatively more resistant than those from vitamin A-normal (VAN) mice to NAD-induced cell death. (c) $\mathrm{P} 2 \mathrm{X}^{+}$small intestinal (SI) $\mathrm{CD} 4^{+} \mathrm{T}$ cells were preferentially depleted by NAD-induced cell death in vivo. Mice were injected intravenously with NAD (10 mg per mouse), and numbers of $\mathrm{CD} 4^{+} \mathrm{T}$ cells were determined by flow cytometry $20 \mathrm{~h}$ after the NAD injection. (d) P2rx $7^{-1-}$ cells are resistant to NADinduced cell death. Cultured CD4 ${ }^{+} \mathrm{T}$ cells from wild-type (WT) and $P 2 r x 7^{-1-}$ mice were treated with NAD as in (a). Representative and combined data ( $n=3$ for $\mathbf{a}, \mathbf{b}$, and $\mathbf{d} ; n=5$ for $\mathbf{c}$ ) are shown. *Significant differences between indicated groups. oATP, oxidized ATP; PBS, phosphate-buffered saline.

(Supplementary Figure 2b). In support of the findings, reanalysis of publicly available transcriptome data (GSE15907) for P2rx7 revealed that $\mathrm{CD}^{+} \mathrm{CD}^{+} 4^{+}$
$\mathrm{CD}_{122}{ }^{+}$memory $\mathrm{T}$ cells, but not $\mathrm{CD}^{+} \mathrm{CD}^{+} \mathrm{L}^{+}$ naïve $\mathrm{T}$ cells, highly expressed this gene (Supplementary Figure 3). 

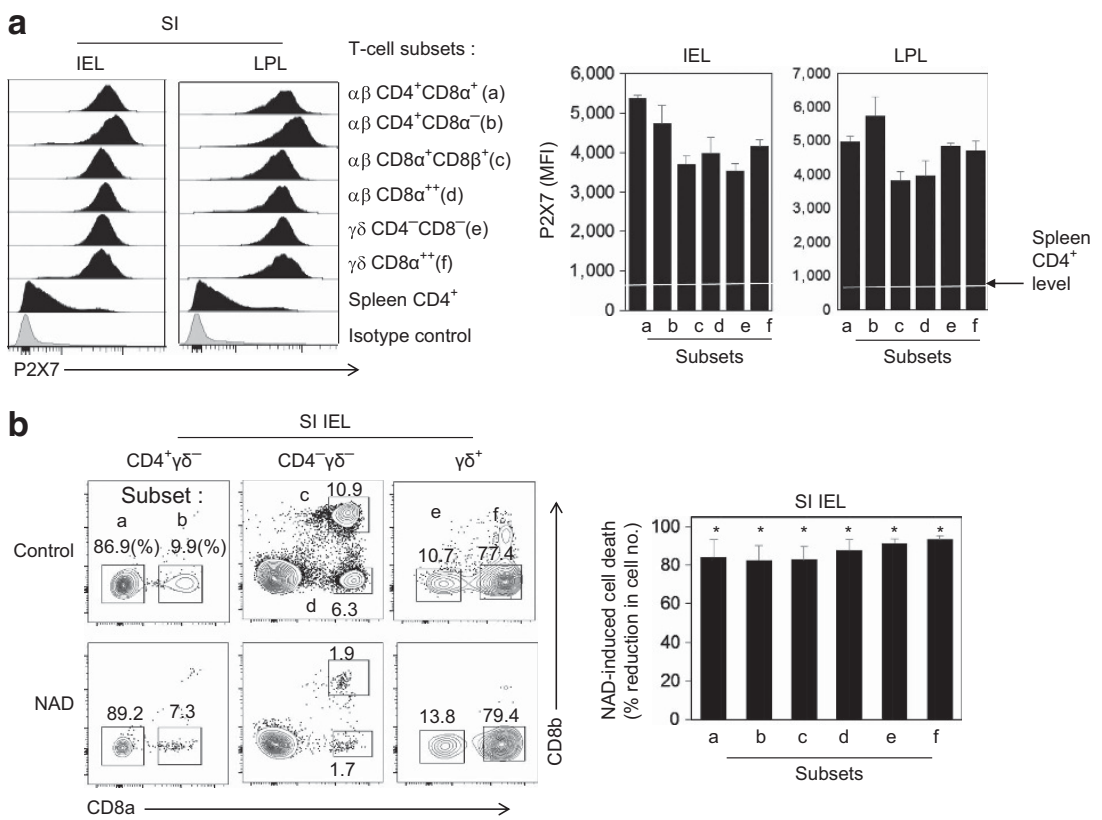

Figure 4 P2X7 expression and nicotinamide adenine dinucleotide (NAD)-induced cell death of $\alpha \beta$ and $\gamma \delta$ T-cell subsets in lamina propria (LP) and intraepithelial compartments. (a) Expression of P2X7 by various $\alpha \beta$ and $\gamma \delta$ T-cell subsets in LP and intraepithelial compartments. (b) NAD-induced cell death of intestinal $\alpha \beta$ and $\gamma \delta$ T-cell subsets. Mice were injected intravenously with NAD (10 mg per mouse), and numbers of CD4 ${ }^{+}$T cells were determined by flow cytometry $20 \mathrm{~h}$ after the NAD injection. Representative and combined data $(n=4$ for $\mathbf{a} ; n=8$ for $\mathbf{b})$ are shown. ${ }^{*}$ Significant differences from control mice. IEL, intraepithelial lymphocyte; LPL, lamina propria lymphocyte; MFI, mean fluorescence intensity; SI, small intestine.

We next investigated if antigen stimulation drives P2X7 expression on intestinal $\mathrm{CD} 4^{+} \mathrm{T}$ cells in vivo. We adoptively transferred ovalbumin-specific OT-II T cells into CD45.1 congenic mice and intragastrically immunized these mice with ovalbumin. The $\mathrm{P} 2 \mathrm{X} 7$ expression on $\mathrm{CD} 4{ }^{+} \mathrm{T}$ cells was induced by ovalbumin, and the OT-II $\mathrm{P} 2 \mathrm{X}^{+}{ }^{+}$cells were detected in the SI and LI but rarely in the spleen and MLN (Figure 5e), indicating that antigen stimulation in the intestinal environment is required for robust induction of $\mathrm{P} 2 \mathrm{X} 7$ expression by $\mathrm{T}$ cells.

\section{P2X7 controls the size of Th1 and Th17 cell populations in the intestine}

Th1 and Th17 cells are major CD4 ${ }^{+}$memory/effector T-cell subsets in the intestine. Because of the preferential expression of $\mathrm{P} 2 \mathrm{X} 7$ by memory/effector T cells in the intestine, we examined P2X7 expression by Th1 and Th17 cells. SI Th1 and Th17 cells highly expressed P2X7 (Figure 6a), which suggests that these effector T cells are likely to be the major targets of P2X7mediated apoptosis. In support of this, high positive correlations were found between the expression of P2X7 and T-bet or ROR $\gamma t$ (retinoid-related orphan receptor- $\gamma \mathrm{t}$ ), the master transcription factors for Th1 or Th17 cells (Figure 6b). The P2X7 expression by intestinal Th1 and Th17 cells was decreased in the VAD compared with the VAN condition (Figure 6c). Moreover, RA induced P2X7 expression on in vitro-generated Th1, Th17, and Th2 cells (Supplementary Figure 4 online). These results identify intestinal Th1 and Th17 cells as potential targets of $\mathrm{P} 2 \mathrm{X} 7$-mediated apoptosis.

A potential function of $\mathrm{P} 2 \mathrm{X} 7$ in the intestine is to induce apoptosis of excessive Th1 and Th17 cells. If this is the case,
P2X7 deficiency would increase the number of Th1 and Th17 cells in the intestine. To test this hypothesis, we examined the size of Th1 and Th17 cell populations in WT vs. $P 2 r x 7^{-1-}$ mice during the steady state and infection by Citrobacter rodentium. The absolute number of Th1 cells in the SI were significantly increased in P2X7-deficient mice in the steady state and this change was even more pronounced during infection by C. rodentium (Figure 7a). The number of Th17 cells was also increased in the SI and LI of P2X7-deficient mice. Interestingly, the abnormal increase of effector $\mathrm{T}$ cells was also observed in the MLN and spleen during infection (Supplementary Figure 5a online). It was also noted that P2X7 expression by $\mathrm{CD}^{+}{ }^{+}$memory/effector cells was increased at variable levels in secondary lymphoid tissues and LI during infection (Supplementary Figure 5b). We next administered NAD into WT and $P 2 r x 7^{-1-}$ mice to determine if Th1 and Th17 cells are effectively depleted in the intestine. NAD injection depleted intestinal Th1 and Th17 cells in WT, but hardly in $P 2 r x 7^{-1-}$, mice following NAD administration or upon NAD treatment ex vivo (Figure $7 \mathbf{b}$ and Supplementary Figure 6a online). In line with the data, Th1, Th17, and Th2 cells, generated in vitro in the presence of RA, were effectively depleted by NAD (Supplementary Figure 6b-d).

We further performed a competitive repopulation study for WT and $P 2 r x 7^{-1-}$ bone marrow (BM) cells to create mice that have both WT and $P 2 r x 7^{-1-}$ hematopoietic cells in the same hosts. The SI had abnormal expansion of $P 2 r x 7^{-1-}$ Th1 and Th17 cells compared with their WT counterparts in the same host (Figure 7c). Similar differences were observed in the MLN but the differences were relatively smaller. These results 
a
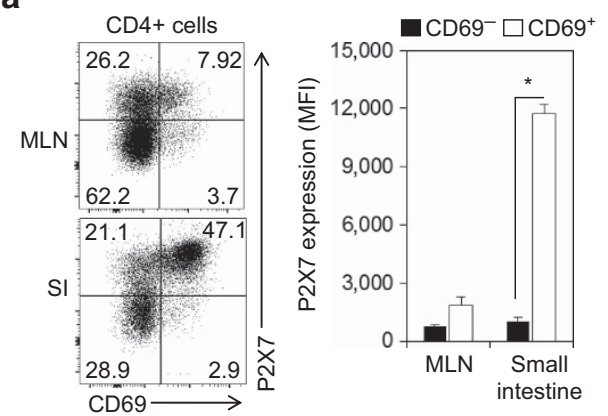

C

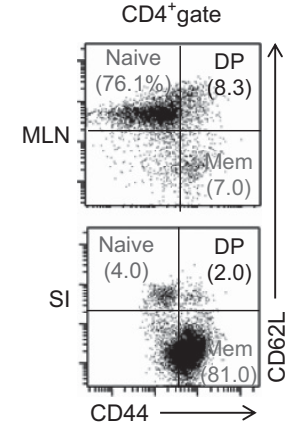

b
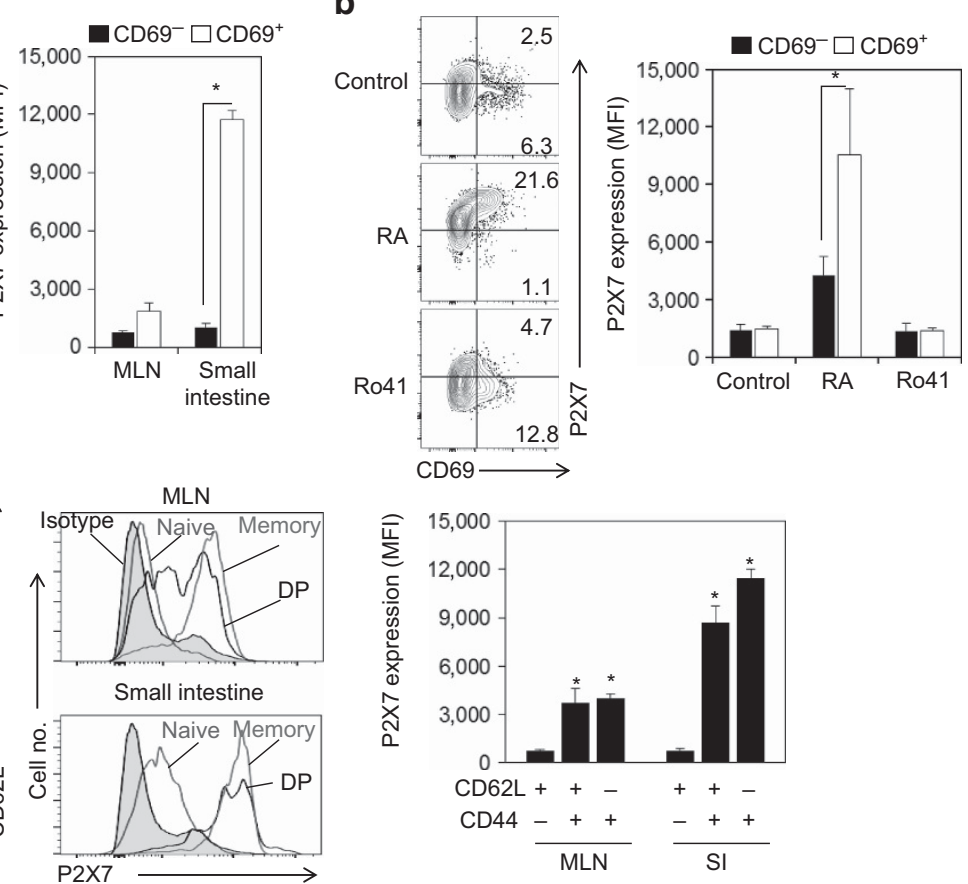

d
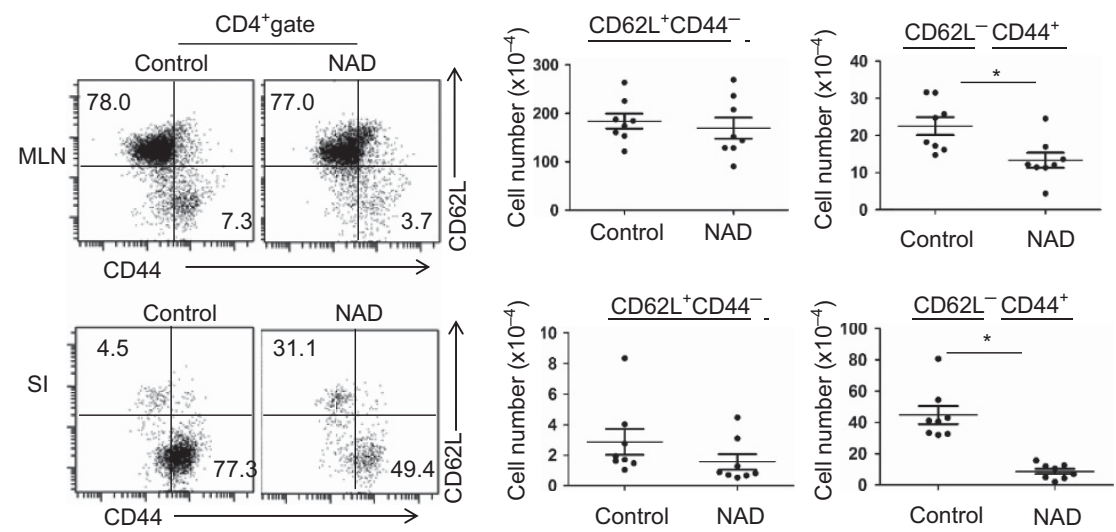

e
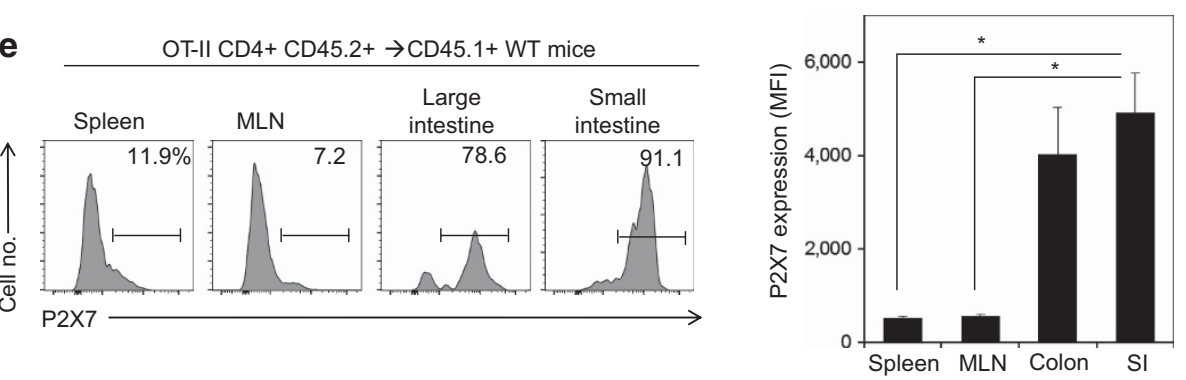

Figure 5 T-cell activation in the presence of retinoic acid (RA) in vitro or in the gut-tissue environment in vivo induces $\mathrm{P} 2 \mathrm{X7}$ expression and increases sensitivity to nicotinamide adenine dinucleotide (NAD)-induced cell death. (a) Expression of P2X7 by $\mathrm{CD} 69^{+} \mathrm{vs}^{-} \mathrm{CD} 69^{-} \mathrm{CD} 4^{+} \mathrm{T}$ cells in small intestine (SI) lamina propria (LP) and mesenteric lymph node (MLN). (b) Expression of P2X7 by CD69+ vs. CD69 ${ }^{-} \mathrm{CD} 4^{+} \mathrm{T}^{+}$cells activated in vitro with RA or Ro41-5253 and concanvalin A. Naïve OT-II CD4 ${ }^{+}$T cells were activated for 4-5 days in the presence of CD11c ${ }^{+}$splenocytes and OVA $_{323-3 з 9}$. (c) Expression of P2X7 by naïve and memory/effector-like CD4 ${ }^{+}$T-cell subsets distinguished by CD44 and CD62L expression. (d) Comparison of gutnaïve and memory/effector CD4 ${ }^{+} \mathrm{T}$-cell subsets for their sensitivity to NAD-induced cell death. (e) Antigenic stimulation induces P2X7 on CD4 ${ }^{+} \mathrm{T}$ cells preferentially in the small and large intestines. CD45.1 $1^{+}$mice were transferred intravenously with naïve CD45.2 ${ }^{+}$OT-II T cells and immunized intragastrically with ovalbumin. Representative and combined data ( $n=5$ for $\mathbf{a}, n=3$ for $\mathbf{b}, n=6$ for $\mathbf{c}, n=7$ for $\mathbf{d}, n=7$ for $\mathbf{e})$ are shown. ${ }^{*}$ Significant differences from the first groups or between indicated groups. MFI, mean fluorescence intensity; WT, wild type. A full color version of this figure is available at the Mucosallmmunology journal online. 
a

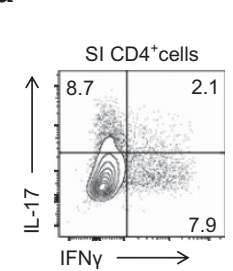

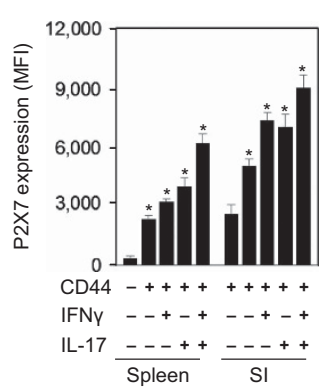

b

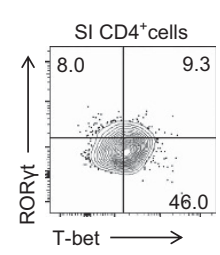

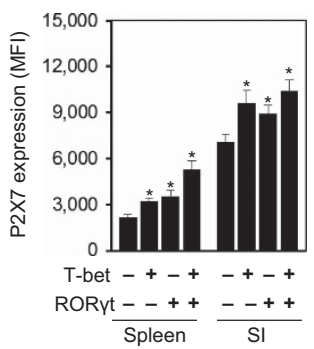

C
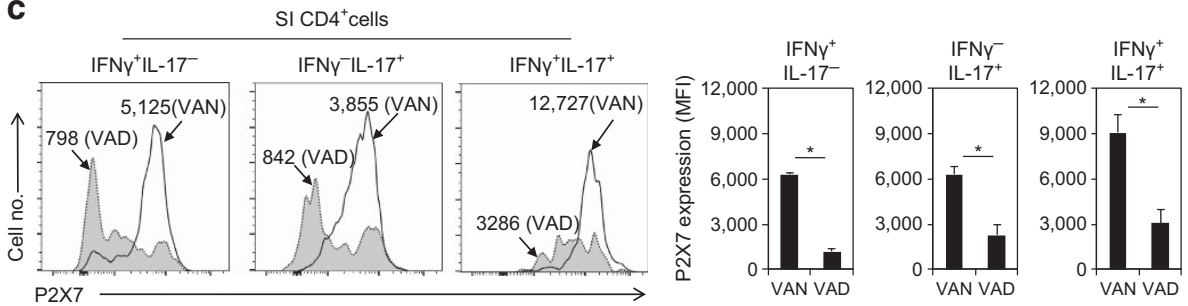

Figure 6 Intestinal T-helper type 1 (Th1) and Th17 effector cells preferentially express P2X7 in a retinoic acid (RA) or vitamin A-dependent manner. (a) P2X7 expression by interferon- $\gamma$ (IFN- $\gamma$ )/interleukin-17 (IL-17)-expressing CD44 ${ }^{+}$vs. non-IFN- $\gamma /$ IL-17-expressing CD44 ${ }^{+}$CD4 ${ }^{+}$cells. (b) Correlation between P2X7 and ROR $\gamma \mathrm{t}$ (retinoid-related orphan receptor- $\gamma \mathrm{t}$ ) or T-bet expression in intestinal T cells. Expression of P2X7, T-bet, and ROR $\gamma$ t by CD4 ${ }^{+}$T cells isolated from indicated tissues of C57BL/6 mice was examined. (c) P2X7 expression by Th1 and Th17 cells in the spleen and small intestine (SI) of vitamin A-normal (VAN) and vitamin A-deficient (VAD) mice. Representative and combined data $(n=7$ for $\mathbf{a}, n=6$ for $\mathbf{b}$ and $\mathbf{c})$ are shown. *Significant differences from the first groups or between two groups. MFI, mean fluorescence intensity.

indicate that $\mathrm{P} 2 \mathrm{X} 7$ is required to prevent the excessive buildup of Th1 and Th17 cell in the intestine.

\section{NAD administration restrained inflammatory intestinal Th1 and Th17 cells and suppressed colitis}

To gain insights into the role of $\mathrm{P} 2 \mathrm{X} 7$ in regulating inflammatory $\mathrm{T}$ cells in the intestine, we next examined $\mathrm{P} 2 \mathrm{X} 7$ expression by $\mathrm{CD} 4^{+} \mathrm{T}$ cells in the T-cell-induced colitis in Rag1 ${ }^{-1-}$ mice. P2X7 expression was upregulated in both the SI and LI of T-cell-transferred Rag1 ${ }^{-1-}$ mice (Figure 8a). The $\mathrm{P} 2 \mathrm{X} 7$ expression levels on inflammatory intestinal $\mathrm{T}$ cells in Rag1 ${ }^{-1-}$ mice were significantly higher compared with that of normal intestinal T cells in control C57BL/6 mice. Particularly, the expression of $\mathrm{P} 2 \mathrm{X} 7$ by CD4 ${ }^{+} \mathrm{T}$ cells in the LI of Rag1 ${ }^{-1-}$ mice was particularly high. This indicates a potentially important role for the P2X7 pathway in reining in inflammatory $\mathrm{T}$ cells. To test this hypothesis, we injected NAD into T-cell-transferred Rag1 ${ }^{-1-}$ mice. Repeated NAD treatment depleted $>\sim 90 \%$ of Th1 in the colitis model (Figure 8b). Moreover, minor populations such as Th17 and FoxP $3^{+}$cells were also depleted. NAD injection suppressed weight loss, inflammation-related colon contraction, and tissue inflammation (Figure 8c-e).

\section{DISCUSSION}

The results of this study reveal an important role of vitamin A metabolites in regulating intestinal effector $\mathrm{T}$ cells through P2X7 upregulation. We identified an enhancer region that makes the murine $P 2 r x 7$ gene sensitive to RA. RA-induced $\mathrm{P} 2 \mathrm{X} 7$ is required to restrain the size of effector T-cell populations in the intestine. This function of $\mathrm{P} 2 \mathrm{X} 7$ is important in suppressing the overpopulation of effector $\mathrm{T}$ cells in intestinal tissues and, therefore, has the potential to prevent T-cell-induced inflammatory diseases in the intestine.

It has been unclear when and how P2X7 is upregulated on $\mathrm{CD}^{+}{ }^{+} \mathrm{T}$ cells during T-cell differentiation. Early studies suggested that $\mathrm{CD}^{+}{ }^{+} \mathrm{T}$ cells in peripheral lymph nodes are sensitive to P2X7-induced cell death. ${ }^{14,29}$ A key question is if there is any specificity in P2X7 expression in terms of cell type, differentiation stage, and tissue location. We systematically compared P2X7 expression by naïve and memory/effector $\mathrm{CD} 4{ }^{+}$T-cell populations in the intestine and lymphoid tissues. Naïve $\mathrm{CD} 4^{+} \mathrm{T}$ cells hardly expressed P2X7 but memory and effector $\mathrm{CD} 4{ }^{+} \mathrm{T}$ cells highly expressed P2X7. Moreover, there were differences among organs (i.e., intestine vs. lymphoid tissues) in $\mathrm{P} 2 \mathrm{X} 7$ expression by $\mathrm{T}$ cells. In the steady state, $\mathrm{CD} 4^{+} \mathrm{T}$ cells in the SI most highly express P2X7, which is followed by those of the LI. In contrast, relatively fewer $\mathrm{CD}^{+} \mathrm{T}$ cells in lymphoid tissues expressed P2X7. Moreover, it was Th1 and Th17 cells that expressed P2X7 most highly in the intestine. Thus, $\mathrm{P} 2 \mathrm{X} 7$ expression is developmentally and tissue specifically regulated in $\mathrm{CD}^{+}{ }^{+} \mathrm{T}$ cells.

A key finding of this study is the identification of an enhancer region in the mouse P2rx7 gene, which induces the gene in response to RA. RA is highly produced by dendritic cells and epithelial cells in the intestine, particularly in the SI. ${ }^{30}$ RA has pleiotropic functions in regulating the immune system. ${ }^{31,32} \mathrm{RA}$ affects the differentiation and function of $\mathrm{T}$ cells and other cell types, ${ }^{26,33-37}$ and induces gut-homing receptors for T-cell migration into the intestines. ${ }^{33,35,37}$ By inducing gut-homing receptors, RA populates the intestine with antigen-experienced effector T cells. While this promotes intestinal immunity, the same function can cause overpopulation of effector $\mathrm{T}$ cells and tissue inflammation. Our transcriptome analysis of RA-treated $\mathrm{T}$ cells indicates that $\mathrm{P} 2 \mathrm{X} 7$ is coexpressed by $\mathrm{T}$ cells that express 
a

WT
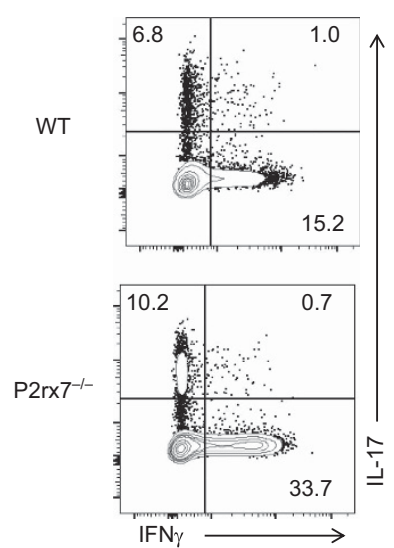

Th1

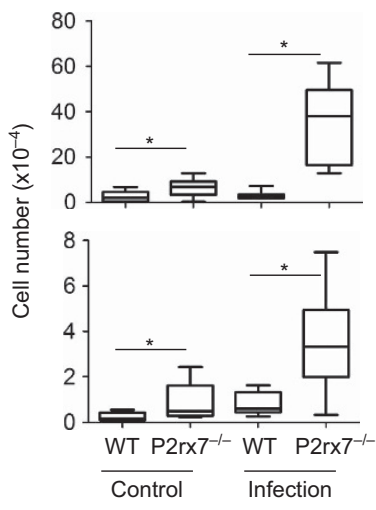

Th17

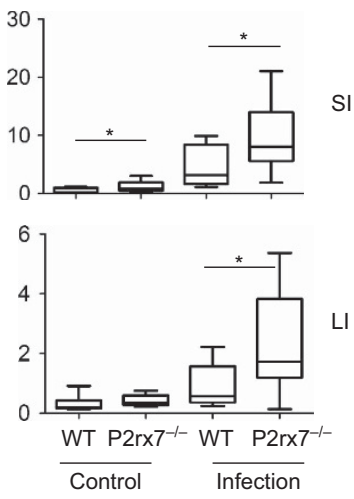

b SI CD4 ${ }^{+} \mathrm{T}$ cells
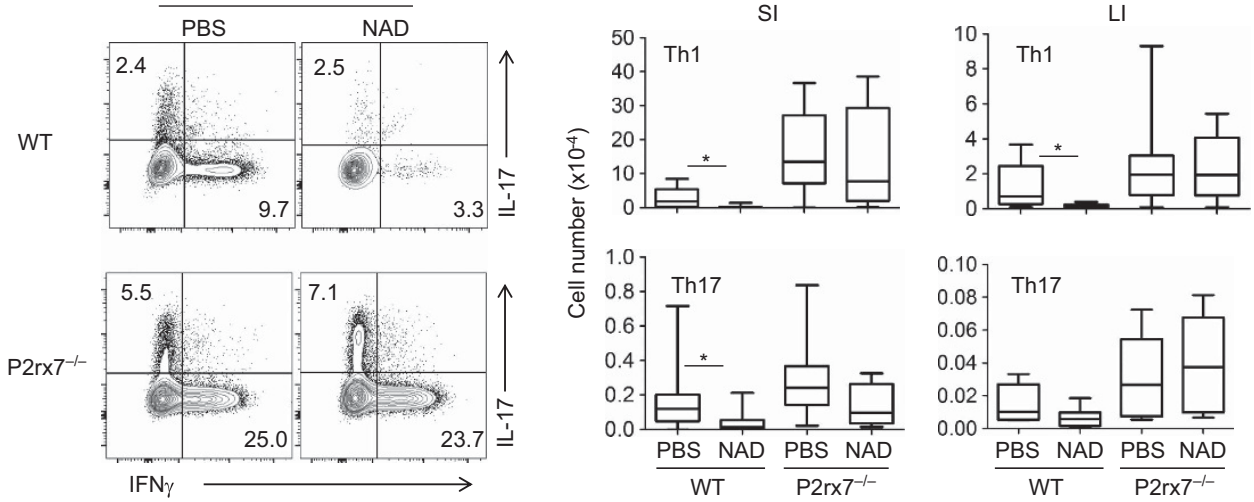

C

Donor (CD45.2+) CD4 ${ }^{+}$T cells (SI)
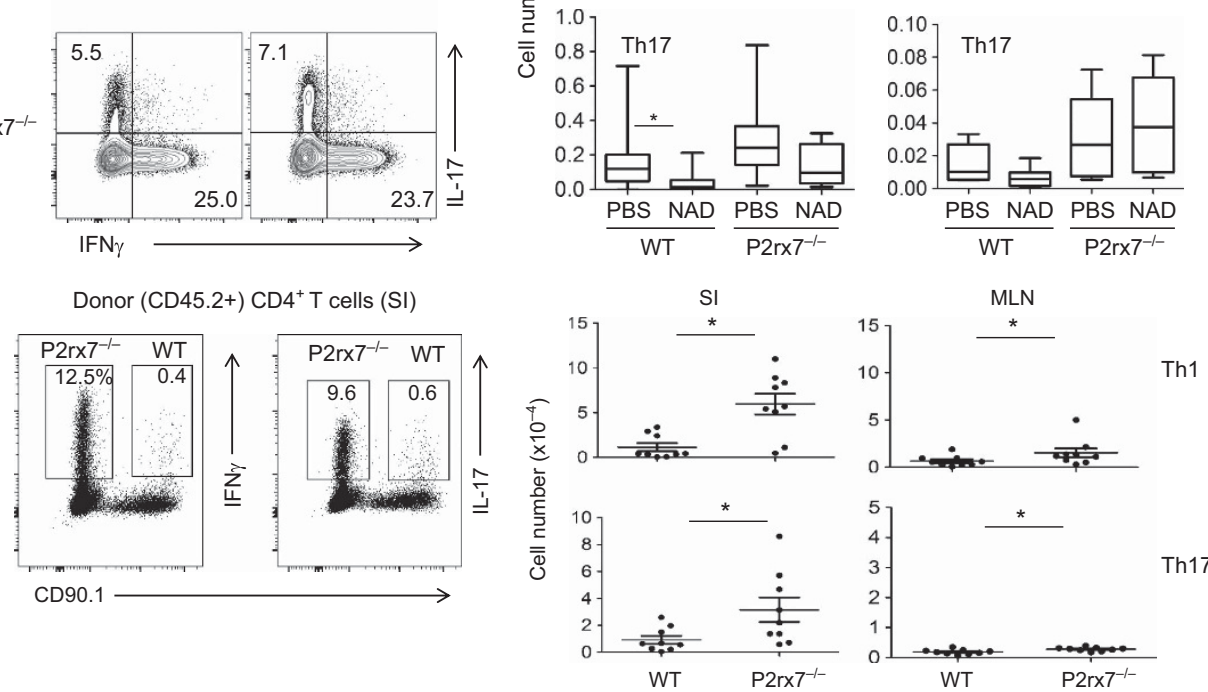

Figure $7 P 2 r x 7^{-1-}$ mice have aberrantly expanded populations of T-helper type 1 (Th1) and Th17 cells in the steady state and during active immune responses. (a) Frequencies and absolute numbers of Th1 and Th17 cells in the intestine of wild-type (WT) and $P 2 r x 7^{-1-}$ mice in the steady state and during Citrobacter rodentium infection. Mice were examined 2 weeks after infection with C. rodentium. (b) Sensitivity of small intestine (SI) WT vs. $P 2 r \times 7^{-1-}$ Th1 and Th17 cells to nicotinamide adenine dinucleotide (NAD)-induced cell death. (c) Th1 and Th17 populations following competitive bone marrow repopulation. A 1:1 mixture of Thy $1.1^{+} \mathrm{CD} 45.2^{+} \mathrm{WT}$ and Thy $1.2^{+} \mathrm{CD} 45.2^{+} \mathrm{P} 2 \mathrm{rx} 7^{-1}$ bone marrow (BM) was transplanted into lethally irradiated CD45.1 ${ }^{+}$congenic mice. The mice were killed 9 weeks post-BM transfer. The boxes and bars, respectively, represent the $25-75$ th and $0-100$ th percentile data ranges. Representative and combined data $(n=11-14$ for $\mathbf{a} ; n=12$ for $\mathbf{b})$ are shown. *Significant differences between two groups. IFN, interferon, IL, interleukin; LI, large intestine; MLN, mesenteric lymph node; PBS, phosphate-buffered saline.

gut-homing receptors such as CCR9 and Itg- $\alpha 4$. This indicates that gut-homing $\mathrm{CD} 4^{+} \mathrm{T}$ cells are a target of $\mathrm{P} 2 \mathrm{X} 7$-mediated apoptosis. It has been reported that RA induces P2X7 expression in intraepithelial CD8 ${ }^{+} \mathrm{T}_{\text {cells. }}{ }^{4}$ Our data indicate that most $\alpha \beta$ and $\gamma \delta$ T-cell subsets in intestinal LP and intraepithelial compartments express $\mathrm{P} 2 \mathrm{X} 7$ and are susceptible to NAD-induced cell death. Therefore, the RA-P2X7 pathway is likely to affect most T-cell subsets in the intestine.

The intestinal tissues harbor many effector $\mathrm{T}$ cells reactive to commensal bacteria and dietary antigens. ATP and NAD, the two P2X7-activating metabolites, are released from stressed or activated cells, which are generated following tissue damage and inflammatory responses. ATP can be also produced by the gut microbiota or host cells upon stimulation with commensal bacteria and pathogens. ${ }^{38,39}$ Our results indicate that intestinal effector T cells are restrained by the P2X7-mediated apoptosis in the steady state and during inflammatory responses. This is supported by the abnormally expanded Th1 and Th17 cell populations in P2X7-deficient mice, particularly during active immune responses such as infection or inflammatory responses. 


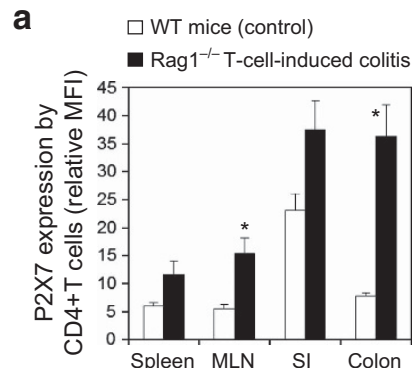

C

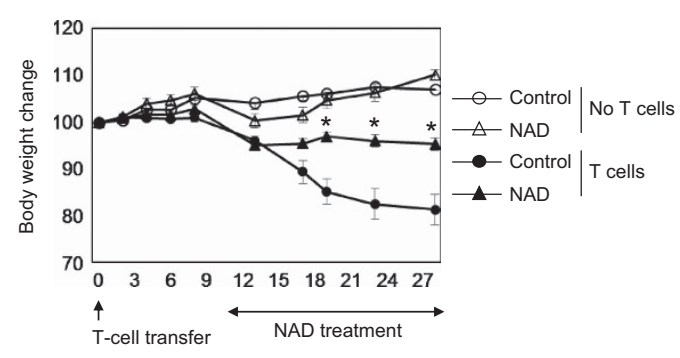

b

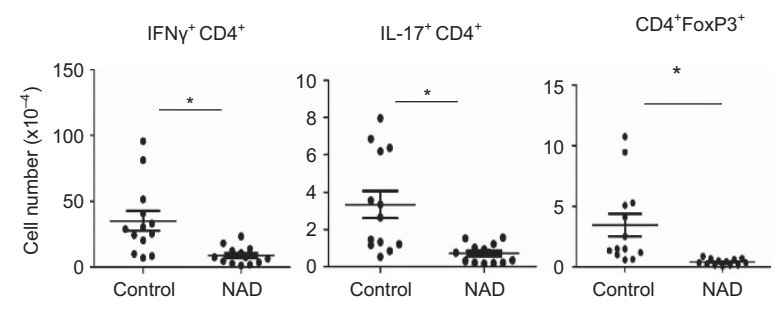

d

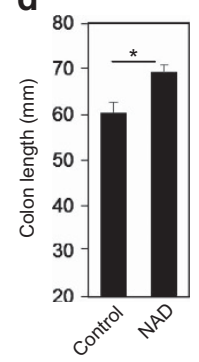

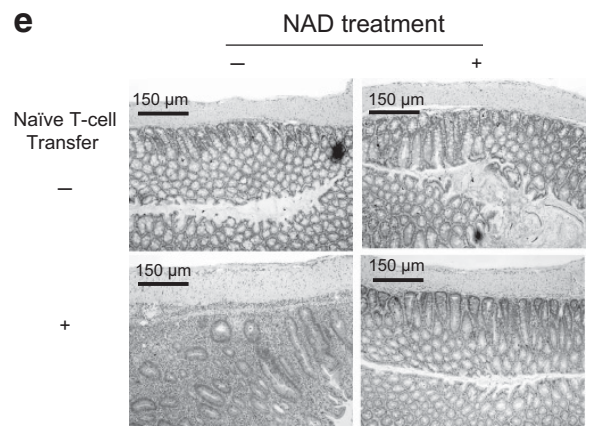

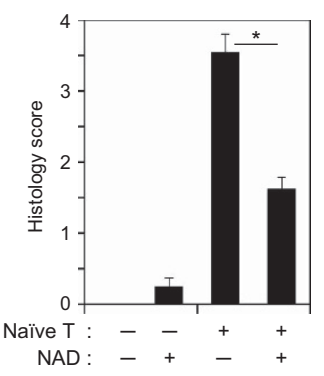

Figure 8 Nicotinamide adenine dinucleotide (NAD) administration depletes inflammatory T cells and suppresses colitis in Rag1 ${ }^{-1-}$ mice. (a) Expression of P2X7 by CD4 ${ }^{+} \mathrm{T}$ cells in Rag $1^{-1-}$ mice following the transfer of naïve CD4 ${ }^{+} \mathrm{T}$ cells. (b) Numbers of T-helper type 1 (Th1) and Th17 cells in in Rag $1^{-1-}$ mice following injection of NAD or phosphate-buffered saline (PBS). (c) NAD suppressed colitis-associated weight loss. (d) NAD suppressed T-cell-induced colitis-associated colon shortening in Rag ${ }^{-1-}$ mice. (e) NAD suppressed tissue inflammation in the distal colon. Hematoxylin and eosin (H\&E) staining and histological assessment were performed. Mice were killed at 4 weeks after naïve T-cell transfer. Representative and combined data ( $n=5$ for $\mathbf{a}, n=13$ for $\mathbf{b}, \mathbf{c}, \mathbf{d}$, and $\mathbf{e}$ ) are shown. *Significant differences from control groups or between two groups. IFN, interferon, IL, interleukin; MFI, mean fluorescence intensity; SI, small intestine; WT, wild type. A full color version of this figure is available at the Mucosallmmunology journal online.

In support of our findings, it has been reported that P2X7deficient mice suffer from more severe inflammatory responses compared with WT mice following infection with Toxoplasma gondii or during an experimental inflammatory response in the central nervous system. ${ }^{40,41}$ This is further supported by our data that NAD administration effectively depleted inflammatory Th1 and Th17 cells and suppressed the T-cell-induced colitis into Rag1 ${ }^{-1-}$ mice. Thus, P2X7 controls the size of activated T-cell populations in the intestine.

P2X7 is also expressed by mouse and human FoxP3 ${ }^{+}$ Tregs. ${ }^{2,42}$ For example, Aswad et al. reported that spleen Tregs express P2X7 and are more susceptible to NAD or ATPinduced apoptosis compared to non-Tregs. ${ }^{22}$ It is true that Tregs in secondary lymphoid tissues such as spleen and lymph nodes express P2X7 at levels higher compared with that by non-Tregs. This is owing to the fact that even naïve-like Tregs express P2X7 at medium levels, whereas conventional non-Treg naïve $\mathrm{CD} 4{ }^{+}$ T cells hardly express P2X7. In the SI, however, non-Treg effector $\mathrm{T}$ cells express $\mathrm{P} 2 \mathrm{X} 7$ at levels higher than Tregs. RA induces $\mathrm{P} 2 \mathrm{X} 7$ also in $\mathrm{FoxP}^{+}{ }^{+} \mathrm{T}$ cells. Therefore, RA-induced P2X7 expression probably affects both effector $\mathrm{T}$ cells and Tregs in the intestine. Because Tregs express P2X7 even at the naïve stage, Tregs may depend less on RA in P2X7 expression than nonTregs. We also observed that antigen stimulation is required to induce $\mathrm{P} 2 \mathrm{X} 7$ expression in naïve $\mathrm{CD} 4{ }^{+} \mathrm{T}$ cells. Thus, the results of our study expand the role of P2X7 to memory/effector T cells, including Th1 and Th17 effector T cells. A recent study revealed that P2X7 controls the function of follicular helper T cells in Peyer's patches. ${ }^{5}$ In this regard, follicular helper T cells are also effector $\mathrm{CD} 4^{+} \mathrm{T}$ cells, specialized in helping B cells.

In summary, effector T cells, including Th1 and Th17 cells, are effectively restrained by P2X7-dependent apoptosis in the intestine. RA induces the expression of P2X7 and ART2.2 in activated $\mathrm{CD} 4^{+} \mathrm{T}$ cells producing effector cytokines. RA induces P2X7 expression through RAR $\alpha$ binding to an enhancer region between exons 2 and 3 on the P2rx7 gene for epigenetic modification and enhanced gene expression. We conclude that RA, the key factor that promotes T-cell migration to the intestine for immunity, also has a significant role in containing the activity of various effector $\mathrm{T}$ cells in the intestine. 
We suggest that this pathway provides a negative feedback loop in the intestinal immune network to suppress aberrant T-cell activity and inflammatory diseases.

\section{METHODS}

Animals and diet. All experiments with animals in this study were approved by the Purdue Animal Care and Use Committee (PACUC). $P 2 r x 7^{-1-}$ mice (stock number 005576) and Rag1 ${ }^{-1-}$ C57BL/6 mice (stock number 002216) were purchased from the Jackson Laboratory (Bar Harbor, ME). VAD and VAN mice were generated by feeding late-term (15-16 days postcoitus) pregnant females with AIN-93G custom diet containing retinyl acetate at $2,500 \mathrm{IU} \mathrm{kg}^{-1}$ of diet for VAN or $0 \mathrm{IU} \mathrm{kg}^{-1}$ of diet for VAD, respectively (TD. 07267 and TD. 00158 ; Harlan Teklad, Indianapolis, IN). The weaned mice were kept on the same diet for at least 10 weeks before the experiment.

Infection and induction of colitis. WT and $P 2 r x 7^{-1-}$ C57BL/6 mice (6 weeks old, sex-matched males or females) were infected intragastrically with $C$. rodentium ( $10^{9}$ colony-forming unit per mouse). $\mathrm{Rag1}^{-1-} \mathrm{C} 57 \mathrm{BL} / 6$ mice were injected intraperitoneally with naïve $\mathrm{CD}^{+} \mathrm{T}$ cells $\left(5 \times 10^{5}\right.$ cells per mouse $)$ to induce colitis. Mice were monitored for weight change and killed 2 or 4 weeks later. The colon was histologically examined after hematoxylin and eosin staining. Colitis scores were assessed based on levels of leukocyte infiltration, loss of normal crypt structure, and mucosae hyperplasia on a scale of 4 by two different researchers. When indicated, NAD (20 mg; SigmaAldrich, St Louis, MO) was injected intraperitoneally every $12 \mathrm{~h}$.

BM or T-cell transfer. Recipient mice were subjected to lethal $\gamma$-irradiation (1,050 rads) and reconstituted intravenously with BM cells from WT and P2rx $7^{-1-}$ mice $\left(4 \times 10^{6}\right.$ cells each). Mice were examined 9 weeks after $\mathrm{BM}$ transplantation. $\mathrm{CD}^{+}$naïve $\mathrm{T}$ cells $\left(2 \times 10^{6}\right.$ cells per mouse), isolated from CD $45.2^{+}$OT-II mice, were transferred intravenously into CD $45.1^{+}$mice and then immunized intragastrically with $\mathrm{OVA}_{323-339}(10 \mu \mathrm{g}$; Sigma-Aldrich) and cholera toxin (10 $\mu \mathrm{g}$; Sigma Aldrich) on days 1 and 14. Mice were killed 5 days after the immunization.

Cell isolation and culture. Naive $\mathrm{CD} 4{ }^{+} \mathrm{T}$ cells, isolated as described previously, ${ }^{37}$ were cultured in complete RPMI-1640 medium supplemented with either regular or charcoal-treated fetal bovine serum. The cells were activated with concanavalin A $\left(1.5 \mu \mathrm{g} \mathrm{ml}^{-1}\right.$; Sigma-Aldrich), $\mathrm{OVA}_{323-339}$ (for DO11.10 Rag2 ${ }^{-/-} \mathrm{CD}^{+}{ }^{+} \mathrm{T}$ cells), or plate-bound anti-CD3 antibody $\left(0.2-2 \mu \mathrm{g} \mathrm{ml}^{-1}\right)$ and soluble antiCD28 antibody $\left(2 \mu \mathrm{g} \mathrm{ml}^{-1}\right)$ (BioXcell, Lebanon, $\mathrm{NH}$ ) with human IL-2 $\left(100 \mathrm{U} \mathrm{ml}^{-1}\right)$ for 3-5 days. Th1, Th17, and Tregs were cultured as described previously. ${ }^{33,37}$ Cytokines were purchased from either BioLegend (San Diego, CA) or PeproTech (Rocky Hill, NJ). T cells were cultured with RA (all-trans RA, 1-10 nM) or Ro41-5253 (100 or $500 \mathrm{~nm}$; Sigma-Aldrich).

Flow cytometry. Cells were stained with anti-P2X7 (clone Hano43; AbD Serotec, Raleigh, NC), anti-rat immunoglobulin G2b (clone MRG2b-85), PerCP/Cy5.5- or PE-Cy7-conjugated streptavidin, antiCD4 (clone RM4-5), anti-interferon- $\gamma$ (clone XMG1.2), anti-IL-17 (clone TC11-18H10.1), anti-FoxP3 (clone FJK-16s), anti-CD44 (clone IM7), anti-CD69 (clone H1.2F3), anti-CD62L (clone MEL-14), antiROR $\gamma t$ (clone AFKJS-9), and/or anti-T-bet (clone eBio-4B10). Most antibodies were purchased from BioLegend or eBioscience (San Diego, CA). For detection of P2X7 on T cells, cells were sequentially stained with anti-P2X7 antibody, biotin-anti-rat immunoglobulin G2b, and fluorochrome-conjugated streptavidin. Intracellular staining of cytokines and other antigens were performed as described previously. $^{33}$

Assessment of NAD-induced T-cell apoptosis. Cultured CD4 ${ }^{+}$ $\mathrm{T}$ cells or cells isolated from the MLNs or SI were treated with NAD ( $\beta$-nicotinamide adenine dinucleotide hydrate; $100-200 \mu \mathrm{M}$; Sigma-
Aldrich) for $2 \mathrm{~h}$ in complete RPMI-1640. When indicated, cells were pretreated with periodate-oxidized ATP (a P2X7 receptor antagonist, $1 \mathrm{~mm}$; Sigma-Aldrich) for $2 \mathrm{~h}$ before the NAD treatment. Cells were then washed two times with ice-cold phosphate-buffered saline, and then stained with antibodies to CD4, CD44, IFN $\gamma$ and IL-17. When indicated, Annexin $\mathrm{V}$ and propidium iodide staining was performed in Annexin $\mathrm{V}$ binding buffer (BioLegend). To assess the short-term depletion effect of NAD on $\mathrm{CD} 4{ }^{+}$T cells in vivo, mice were injected intravenously with NAD $(10 \mathrm{mg})$ and killed 2 or $20 \mathrm{~h}$ later. The results obtained at 2- and 20-h time points were similar and all data shown in this report were obtained at the 20 -h time point.

ChIP assay. RAR $\alpha$ binding and $\mathrm{H} 3$ acetylation sites on the $P 2 r x 7$ gene were identified by analyzing publicly available ChIP-sequencing data (GSE60356) with Integrated Genome Browser (IGB Bioinformatics Application Note). To determine RA-dependent regulation of RAR $\alpha$ binding and $\mathrm{H} 3$ acetylation sites on the P2rx7 gene, a ChIP assay was performed with the SimpleChiP Kit (Cell Signaling Technologies, Danvers, MA) using the primers described in Supplementary Table 1 online. Immunoprecipitation was performed using rabbit control immunoglobulin G or polyclonal antibody to h/mRAR $\alpha$ (Santa Cruz Biotech, Santa Cruz, CA) or acetylated H3 (Millipore, Temecula, CA). Eluted DNA was analyzed by real-time reverse transcription-PCR using primers described in Supplementary Table 1.

Transfection and reporter assay. The $2.3 \mathrm{~kb} P 2 r x 7$ promoter and $1.6 \mathrm{~kb}$ enhancer regions $(-2,337$ to -1 and $+8,828$ to $+10,409$ from TSS, respectively) were amplified with primers shown in Supplementary Table 1 online and cloned into pGL4.10 (Promega, Madison, WI). $\mathrm{CD} 4{ }^{+} \mathrm{T}$ cells $\left(3 \times 10^{6}\right)$ were activated for 2 days with anti-CD3/CD28 antibodies and transfected using the Mouse T-Cell Nucleofector Kit (Lonza, Allendale, NJ). Transfected cells were cultured for $6 \mathrm{~h}$ in complete RPMI with charcoal-treated fetal bovine serum (10\%) with or without RA $(20 \mathrm{~nm})$ before measuring luciferase activity with the Luciferase Reporter Kit (Promega). Transfection efficiency in T cells was assessed by quantitative PCR of transfected plasmids 2 days after transfection.

Confocal microscopy. SI tissues (ileum) was harvested from C57BL/6 mice ( 7 weeks old) and frozen in Tissue-Tek OCT Compound (Sakura Finetek, Torrance, CA). Tissue blocks were cut into $8 \mu \mathrm{m}$ sections, fixed in acetone, and stained with antibodies to mP2X7 (Hano43), CD4 (RM4-5), and CD69 (H1.2F3). The images were obtained with a Leica SP5 II confocal system (Buffalo Grove, IL).

Quantitative real-time PCR and microarray data analyses. Total RNA was extracted with TRIzol (Invitrogen, Grand Island, NY), and cDNA synthesis was performed with the High-Capacity cDNA Reverse Transcription Kit (Invitrogen). Quantitative real-time PCR was performed with Maxima SYBR Green/ROX qPCR Master Mix (Thermo Scientific, Grand Island, NY) using the primers described in Supplementary Table 1 online. $\beta$-Actin expression was also measured for data normalization. Microarray data (GSE20500 and GSE15907) were described previously. ${ }^{43,44}$ All plots were made with the multiplot module of GenePattern.

Statistics. Statistical significance of differences between indicated groups was obtained by Student's $t$-test and two-way analysis of variance. $P$ values $<0.05$ were considered significant. Error bars in all figures indicate s.e.m.

SUPPLEMENTARY MATERIAL is linked to the online version of the paper at http://www.nature.com/mi

\section{ACKNOWLEDGMENTS}

We thank J.H. Park (Purdue University) for his helpful input. This study was supported, in part, by grants from National Multiple Sclerosis Society and $\mathrm{NIH}$ (R01Al074745, R01DK076616, 1S10RR02829, R01Al080769, and R01Al121302) to C.K. 


\section{AUTHOR CONTRIBUTIONS}

S.H. performed experiments, analyzed data, and prepared most of the figures with experimental contributions from L.F. and M.K. C.K. conceived the project and obtained funding; analyzed data and drafted the manuscript with S.H.

\section{DISCLOSURE}

The authors declared no conflict of interest.

c 2017 Society for Mucosal Immunology

\section{REFERENCES}

1. Yang, Y. et al. Focused specificity of intestinal $\mathrm{TH} 17$ cells towards commensal bacterial antigens. Nature 510, 152-156 (2014).

2. Marrack, P., Scott-Browne, J. \& MacLeod, M.K. Terminating the immune response. Immunol. Rev. 236, 5-10 (2010).

3. McKinstry, K.K., Strutt, T.M. \& Swain, S.L. Regulation of CD4 + T-cell contraction during pathogen challenge. Immunol. Rev. 236, 110-124 (2010).

4. Heiss, K. et al. High sensitivity of intestinal CD8 + T cells to nucleotides indicates P2X7 as a regulator for intestinal T cell responses. J. Immunol. 181, 3861-3869 (2008).

5. Proietti, M. et al. ATP-gated ionotropic P2X7 receptor controls follicular T helper cell numbers in Peyer's patches to promote host-microbiota mutualism. Immunity 41, 789-801 (2014).

6. Rissiek, B., Haag, F., Boyer, O., Koch-Nolte, F. \& Adriouch, S. ADPribosylation of P2X7: a matter of life and death for regulatory $T$ cells and natural killer T cells. Curr. Top. Microbiol. Immunol. 384, 107-126 (2015).

7. Hildeman, D.A. et al. Reactive oxygen species regulate activation-induced T cell apoptosis. Immunity 10, 735-744 (1999).

8. Brenner, D., Krammer, P.H. \& Arnold, R. Concepts of activated Tcell death. Crit. Rev. Oncol. Hematol. 66, 52-64 (2008).

9. Sharma, V., Delgado, M., Ganea, D. \& Granzyme, B. A new player in activation-induced cell death, is down-regulated by vasoactive intestinal peptide in Th2 but not Th1 effectors. J. Immunol. 176, 97-110 (2006).

10. Strasser, A., Jost, P.J. \& Nagata, S. The many roles of FAS receptor signaling in the immune system. Immunity 30, 180-192 (2009).

11. Khakh, B.S. \& North, R.A. P2X receptors as cell-surface ATP sensors in health and disease. Nature 442, 527-532 (2006).

12. Adriouch, S. et al. ADP-ribosylation at R125 gates the P2X7 ion channel by presenting a covalent ligand to its nucleotide binding site. FASEB J. 22, 861-869 (2008).

13. Trabanelli, S. et al. Extracellular ATP exerts opposite effects on activated and regulatory $\mathrm{CD} 4+\mathrm{T}$ cells via purinergic P2 receptor activation. J. Immunol. 189, 1303-1310 (2012).

14. Seman, M. et al. NAD-induced Tcell death: ADP-ribosylation of cell surface proteins by ART2 activates the cytolytic P2X7 purinoceptor. Immunity 19 , 571-582 (2003).

15. Rissiek, B., Haag, F., Boyer, O., Koch-Nolte, F. \& Adriouch, S. P2X7 on mouse Tcells: one channel, many functions. Front. Immunol. 6, 204 (2015).

16. Dubyak, G.R P2X7 receptor regulation of non-classical secretion from immune effector cells. Cell. Microbiol. 14, 1697-1706 (2012).

17. Di Virgilio, F. et al. P2 purinoceptors in the immune system. Ciba Found. Symp. 198, 290-302. discussion 302-295 (1996).

18. Piccini, A., Carta, S., Tassi, S., Lasiglie, D., Fossati, G. \& Rubartelli, A. ATP is released by monocytes stimulated with pathogen-sensing receptor ligands and induces IL-1beta and IL-18 secretion in an autocrine way. Proc. Natl Acad. Sci. USA 105, 8067-8072 (2008).

19. Franceschini, A. et al. The $P 2 X 7$ receptor directly interacts with the NLRP3 inflammasome scaffold protein. FASEB J. 29, 2450-2461 (2015).

20. Kurashima, Y. et al. Extracellular ATP mediates mast cell-dependent intestinal inflammation through P2X7 purinoceptors. Nat. Commun. 3, 1034 (2012).

21. Scheuplein, F. et al. NAD + and ATP released from injured cells induce P2X7-dependent shedding of CD62 L and externalization of phosphatidylserine by murine T cells. J. Immunol. 182, 2898-2908 (2009).
22. Aswad, F., Kawamura, H. \& Dennert, G. High sensitivity of CD4 + CD25 + regulatory $T$ cells to extracellular metabolites nicotinamide adenine dinucleotide and ATP: a role for P2X7 receptors. J. Immunol. 175, 3075-3083 (2005).

23. Gu, B.J. et al. A Glu-496 to Ala polymorphism leads to loss of function of the human P2X7 receptor. J. Biol. Chem. )276, 11135-11142 (2001).

24. Fernando, S.L. et al. A polymorphism in the P2X7 gene increases susceptibility to extrapulmonary tuberculosis. Am. J. Respir. Crit. Care Med. 175, 360-366 (2007).

25. Adriouch, S., Hubert, S., Pechberty, S., Koch-Nolte, F., Haag, F. \& Seman., $\mathrm{MNAD}+$ released during inflammation participates in T cell homeostasis by inducing ART2-mediated death of naive Tcells in vivo. J. Immunol. 179, 186-194 (2007).

26. Brown, C.C. et al. Retinoic acid is essential for Th1 cell lineage stability and prevents transition to a Th17 cell program. Immunity 42, 499-511 (2015).

27. Shlyueva, D., Stampfel, G. \& Stark, A. Transcriptional enhancers: from properties to genome-wide predictions. Nat. Rev. Genet. 15, 272-286 (2014).

28. Adriouch, S., Dox, C., Welge, V., Seman, M., Koch-Nolte, F. \& Haag, F. Cutting edge: a natural P451L mutation in the cytoplasmic domain impairs the function of the mouse P2X7 receptor. J. Immunol. 169, 4108-4112 (2002).

29. Haag, F. et al. T cells of different developmental stages differ in sensitivity to apoptosis induced by extracellular NAD. Dev. Immunol. 9, 197-202 (2002).

30. Iwata, M. Retinoic acid production by intestinal dendritic cells and its role in T-cell trafficking. Semin. Immunol. 21, 8-13 (2009).

31. Kim, C.H. Retinoic acid, immunity, and inflammation. Vitam. Horm. 86, 83-101 (2011).

32. Hall, J.A., Grainger, J.R., Spencer, S.P. \& Belkaid, Y. The role of retinoic acid in tolerance and immunity. Immunity 35, 13-22 (2011).

33. Kang, S.G., Lim, H.W., Andrisani, O.M., Broxmeyer, H.E. \& Kim, C.H Vitamin A metabolites induce gut-homing FoxP3 + regulatory $T$ cells. J. Immunol. 179, 3724-3733 (2007).

34. Mucida, D. et al. Reciprocal TH17 and regulatory T cell differentiation mediated by retinoic acid. Science 317, 256-260 (2007).

35. Iwata, M., Hirakiyama, A., Eshima, Y., Kagechika, H., Kato, C. \& Song, S.Y. Retinoic acid imprints gut-homing specificity on T cells. Immunity 21, 527-538 (2004).

36. Hall, J.A. et al. Essential role for retinoic acid in the promotion of CD4(+) T cell effector responses via retinoic acid receptor alpha. Immunity 34 , 435-447 (2011).

37. Wang, C., Kang, S.G., HogenEsch, H., Love, P.E. \& Kim, C.H. Retinoic acid determines the precise tissue tropism of inflammatory Th17 cells in the intestine. J. Immunol. 184, 5519-5526 (2010).

38. Atarashi, K. et al. ATP drives lamina propria $T(H) 17$ cell differentiation. Nature 455, 808-812 (2008).

39. Puhar, A., Tronchere, H., Payrastre, B., Nhieu, G.T. \& Sansonetti, P.J. A Shigella effector dampens inflammation by regulating epithelial release of danger signal ATP through production of the lipid mediator Ptdlns5P. Immunity 39, 1121-1131 (2013).

40. Miller, C.M. et al. Lack of a functioning P2X7 receptor leads to increased susceptibility to toxoplasmic ileitis. PLOS One 10, e0129048 (2015).

41. Chen, L. \& Brosnan, C.F. Exacerbation of experimental autoimmune encephalomyelitis in P2X7R - / - mice: evidence for loss of apoptotic activity in lymphocytes. J. Immunol. 176, 3115-3126 (2006).

42. Cortes-Garcia, J.D. et al. Evaluation of the expression and function of the P2X7 receptor and ART1 in human regulatory T-cell subsets. Immunobiology 221, 84-93 (2016).

43. Heng, T.S. \& Painter, M.W. Immunological Genome Project C. The Immunological Genome Project: networks of gene expression in immune cells. Nat. Immunol. 9, 1091-1094 (2008).

44. Kang, S.G., Park, J., Cho, J.Y., Ulrich, B. \& Kim, C.H. Complementary roles of retinoic acid and TGF-beta1 in coordinated expression of mucosal integrins by T cells. Mucos. Immunol. 4, 66-82 (2011). 